\title{
Analysis of Human Error as a Factor in Road Crash in Metro Manila (2005-2015)
}

\author{
Sophia Francesca D. Lu, MOS${ }^{1}$ and Jinky Leilanie Lu, MOH, PhD² \\ ${ }^{1}$ School of Labor and Industrial Relations, University of the Philippines Diliman \\ ${ }^{2}$ National Institutes of Health, University of the Philippines Manila
}

\begin{abstract}
Introduction. In the Philippines, data on road traffic injuries show that road injury is the $11^{\text {th }}$ leading cause of premature deaths in the Philippines. The World Health Organization estimates that 1.24 million die globally due to road traffic crashes.
\end{abstract}

Objectives. This study aimed to show the trend of the road crash situation in Metro Manila, Philippines, over eleven years (2005-2015) and to analyze human error and other associated hazard factors for road crashes.

Methods. This study is a secondary analysis of an 11-year database culled from 2005-2015, for Metro Manila, Philippines. The variables included road crash classification, incidence over months and time of the day, road crash disaggregated by location, region, and city, and type of vehicle. Descriptive statistics were used to describe the incidence of a road crash, road crash fatalities, and risk factors associated with a road crash in Metro Manila.

Results. The incidence of road crashes in Metro Manila has increased from 65,111 in 2005 to 95,615 in 2015. Fatalities also increased from 348 to 536 . The most predominant type of vehicle involved in road crashes were cars from $46 \%$ to $67 \%$, followed by jeepneys, vans, and motorcycles. The most commonly reported human errors were speeding, inattentive and bad turning. The reported percentage of speeding from 2005-2010 ranged between 32\% and 58\%. In 2014, speeding (96\%) was the most reported human error among the other reported errors; such as inattentiveness (range, 28 to 41\%) and bad turning (0.6\% and 33\%). Fatigue and traffic violation made up 0.02\% to $0.45 \%$ of the reported human factors of road crash-related hospitalization cases in Metro Manila for the period. Suspected alcohol use accounted for $0.04 \%$ to $4.57 \%$ of the human errors reported. For non-fatal and fatal crashes, the associated human errors were suspected alcohol use, inattentiveness, and speeding. The highest adjusted residual for both fatal and non-fatal (injurious) crashes was for inattentiveness. Human error was associated with years, suggesting that for some years, the number of crashes caused by human errors is significantly higher than expected. Alcohol-suspected crashes are significantly higher than expected for 2005 and 2011, with 2011 having the highest adjusted residual. Inattentiveness-caused crashes were significantly higher than expected for years 2005 to 2010, with 2007 having the highest adjusted residual. Bad turning was significantly higher from 2005 to 2007; while disobedience was significantly higher for 2005 to 2008. Speeding was significantly higher than expected from 2005 to 2010.

Conclusion. There is a need to address the public health concern posed by road crashes in Metro Manila, as well as to rectify the ergonomically related risk factors and human error components in a road crash.

Key Words: ergonomically-related risk factors, human error, road crash

\section{INTRODUCTION}

Road traffic crash occurs when a vehicle collides with

Corresponding author: Sophia Francesca D. Lu School of Labor and Industrial Relations University of the Philippines Diliman R P De Guzman, UP Diliman, Diliman, Quezon City Email: sdlu@up.edu.ph another vehicle, pedestrian, animal, road debris, or other stationary obstruction and results in injury, death, and property damage. Road traffic injuries have been a major public health crisis with the number of non-fatal injuries from road crashes estimated to be as high as 50 million. ${ }^{1}$ According 
to the World Health Organization (WHO) report, there are about 1.24 million deaths globally due to road traffic crashes, which is an estimated 3,400 deaths every day. The majority of road crashes occur in low- and middle-income countries. ${ }^{1}$ Hence, road traffic injury is one of the leading causes of death around the world.

In the Philippines, data on road traffic injuries show that road injury is the $11^{\text {th }}$ leading cause of premature deaths in the Philippines based on the Global Burden of Diseases, Injuries, and Risk Factors Study conducted in 2010 by the Department of Health. ${ }^{2}$ Relative to other injuries, interpersonal violence was ranked 6 th, drowning at 17 th, and self-harm (suicide) at $27^{\text {th }}$ in the country. ${ }^{2}$ Accident is the 5 th leading cause of mortality from 2005-2010, affecting mostly the young population as reported by the Philippine Health Statistics of the National Epidemiology Center. ${ }^{2}$ Based on the Online National Electronic Injury Surveillance System for 2010-2012 of the Department of Health, transport or vehicular crash is the leading cause of unintentional injuries. ${ }^{2}$

The objectives of the study were: 1 ) to show the trends over eleven years (2005-2015) the road crash situation in Metro Manila, Philippines; and 2) to analyze the human error associated with road crashes in the Philippines.

\section{METHODOLOGY}

This study is a secondary analysis of an 11-year database culled from 2005-2015 for Metro Manila, Philippines. The data came from the Metro Manila Development Authority's (MMDA) Metro Manila Accident Recording and Analysis System (MMARAS). MMARAS is a road crash reporting system for Metro Manila that is created and operated by the Road Safety Unit (RSU) of the MMDA-Traffic Discipline Office-Traffic Engineering Center (MMDA-TDO-TEC), with the cooperation and assistance of the Traffic Enforcement Unit (TEU) of the Philippine National Police (PNP). Road crash reports from MMDA enforcers as well as blotter reports from PNP precincts in Metro Manila are collected and stored in the MMARAS. The objective of the MMARAS is to maintain a database of road crash incidents and to determine areas where safety improvement measures need to be made.

MMARAS classifies road crash incidents into three categories: damage to property, non-fatal, and fatal. A fatal crash is defined as a crash where at least one road user is killed; non-fatal crashes are defined as crashes with at least one injured road user but no fatalities; and damage to property crashes are crashes without fatalities and injured users. MMARAS also records vehicle types involved in road crash incidents. The vehicle types include cycle/pedicab, defined as a human-powered vehicle; motorcycle, a twowheeled mechanically propelled vehicle; motor-tricycle, a three-wheeled passenger-carrying mechanically propelled vehicle; car, a privately-owned mechanically propelled vehicle, including all forms of private-use small passenger-carrying vehicles; jeepney/taxi/FX/bus, "public utility vehicles" that carries passengers for payment of a fee; van, a small vehicle for carrying goods; and trucks, large vehicles for carrying goods. MMARAS categorized accident causations as human error, vehicle defect, others, and no accident factor. In this study, we tried to isolate specific subcategories such as 'alcohol suspected,'speeding, inattentiveness, and other human errors. The category 'other human errors' was stated as is in the database without further specification. Hence, it could not be further disaggregated.

Data were encoded and analyzed using SPSS 23.0. and Microsoft Excel. To explore the hazard factors associated with road crashes in Metro Manila, descriptive statistics were generated from the MMARAS database. Descriptive statistics were presented as graphs, charts, and tables to see the trend and distribution of variables being investigated in the study. Chi-squared test of association was used to look for associations between human error and road crashes.

The study was registered with the Research Grants Administration Office and the Research Ethics Board of the University of the Philippines Manila.

\section{RESULTS}

\section{Road Crash-Related Hospitalization Cases for the period 2005-2015 in Metro Manila}

The number of road crashes in Metro Manila generally increased between 2005 and 2015 (Figure 1). The total number of road crashes reported over the 11 years is 830,699 , while the total number of road crash fatalities is 4270 . Road crashes increased from 65,111 in 2005 to 95,615 in 2015. Similarly, the number of road crash-related fatalities also increased at an alarming pace in the 11 years from 20052015. Fatalities increased from 348 in 2005 to 536 in 2015. The increasing incidence of road crashes corresponds to an increasing number of road crash fatalities.

\section{Distribution of Crash Categories}

Each classification of a road crash has an increasing trend. Damage to property crashes increased 3.9\% every year on average from 2005 to 2015 . On the other hand, non-fatal crashes increased $4.8 \%$ every year on average, while fatal crashes had the highest rate of increase at an average of $6.03 \%$ every year (Table 1 ).

\section{Road Crash-Related Factors}

There is relatively the same proportion over the years for the various months, except for a relatively higher incidence report during December (Figure 2).

Road crashes mostly occurred between 07:00 and 19:00 GMT of the day in the 11 years. Notably, there was a sharp increase in 15:00. Road crashes peaked at 10:00-11:00 and 15:00 of the day (Figure 3).

The southern and central part of Metro Manila recorded the highest number of road crashes throughout the 11 years. The incidence of a road crash in the southern part ranges 


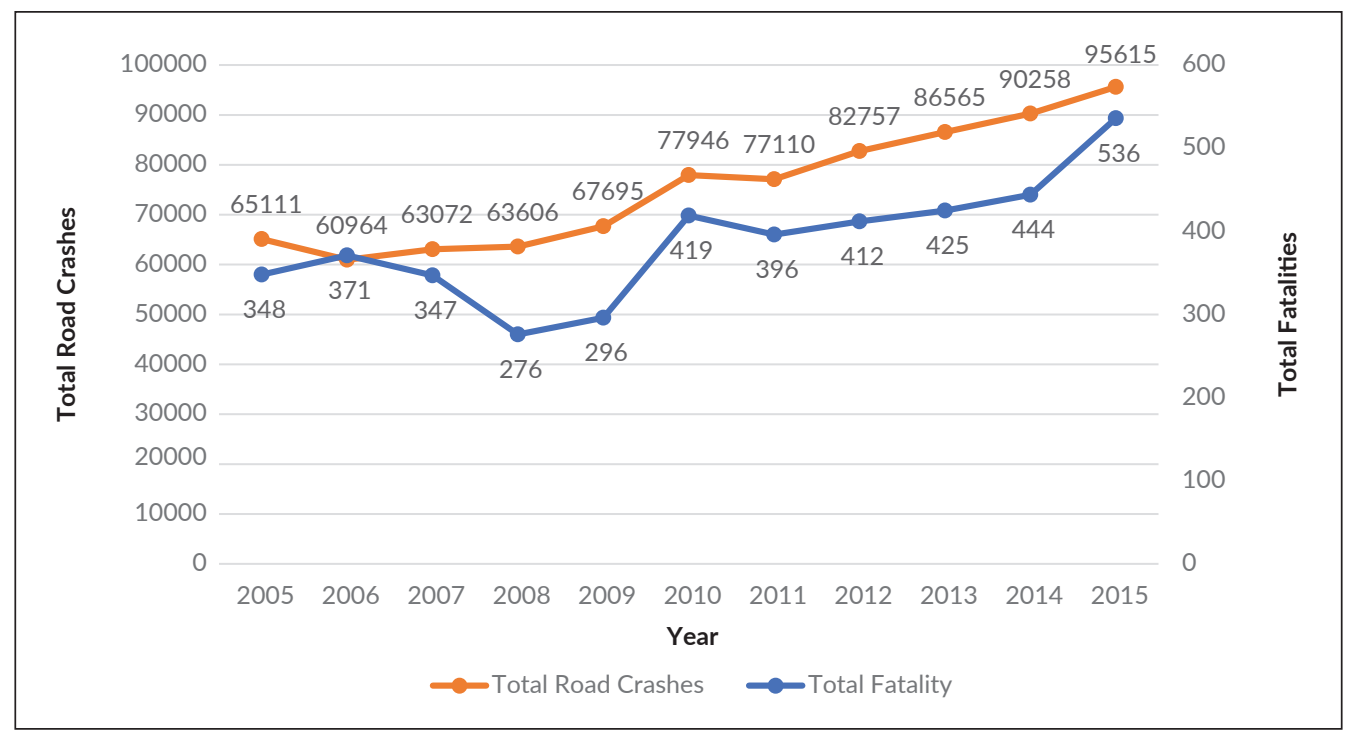

Note: The total number of road crashes was 830,699, while the total number of fatalities was 4,270.

Figure 1. Total road crashes and fatalities in Metro Manila (2005-2015).

between $31 \%$ and $36 \%$ from 2005 to 2015 . About 28\%-33\% of the road crash occurred in the central part from 2005 to 2015 .

The city with the highest number of road crashes reported throughout the ten years was Quezon City, followed by Makati City and the city of Manila. About $28-33 \%$ of the reported road crashes happened in Quezon City, 8-12\% in Makati City, and 6-12\% in the city of Manila (Figure 4).

The most predominant type of vehicle involved in road crashes during the 11 years (2005-2015) was cars (46\% to $67 \%$ of the total reported road crashes in each year). This was followed by jeepney, van, and motorcycles. Road crashes involving buses accounted for about 4-7\% of the total reported crashes each year (Figure 5).

Table 1. Distribution of Classification of Crash from 2005 to 2015

\begin{tabular}{cccc}
\multirow{2}{*}{ Year } & \multicolumn{3}{c|}{ Classification of Crash } \\
\cline { 2 - 4 } 2005 & Damage to Property & Non-Fatal & Fatal \\
2006 & 53915 & 10870 & 324 \\
2007 & 49421 & 11176 & 367 \\
2008 & 51354 & 11380 & 338 \\
2009 & 51084 & 12252 & 269 \\
2010 & 55129 & 12289 & 277 \\
2011 & 62133 & 15423 & 391 \\
2012 & 60943 & 15838 & 370 \\
2013 & 65656 & 16710 & 394 \\
2014 & 69410 & 16744 & 411 \\
2015 & 73175 & 16665 & 418 \\
\hline Total & 77913 & 17103 & 519 \\
\hline
\end{tabular}

\section{Ergonomic Factors}

The ergonomic factors associated with road crashes in Metro Manila from 2005 to 2015 were categorized as vehicle defects, road defects, and human errors. The information for ergonomic factors was missing on $84.81 \%$ of road crash incidents recorded. In 2005, only $24.66 \%$ of the data had a crash factor, which increased to $45.1 \%$ in 2006 , but it dropped continuously to only $2.5 \%$ for 2015 . However, there was a total of 830,699 road crashes from 2005-2015. Hence, the total number of cases with human error reported was 126,174 cases, which is still a significant number. Analysis of the valid observations, however, show that human error was the most common factor leading to a road crash. accounting for at least 2350 to 26998 road crash incidents every year (Figure 6). Vehicle defects (5 to 164 road crashes per year) and road defects (up to 22 road crashes every year) were less commonly reported but still contributed to a non-negligible number of road crash incidents. The spike in the reporting for speeding may be due to the implementation of a $50 \mathrm{kph}$ speed limit in all the radial and circumferential roads in Metro Manila by MMDA. Hence, the trend should have shifted from that year and continuously increased. However, the reports seem to suggest that the reporting for speeding has yet again dropped for 2015, suggesting that the spike was due to inconsistent reporting rather than the actual programs implemented.

\section{Human Error Factor}

From 2005 to 2010, the most commonly reported human errors were speeding, inattentive and bad turning. The reported percentage of speeding from 2005-2010 ranges between 32\% and 58\%. In 2014, speeding (96\%) was the most commonly reported human error among the other reported errors. The reported percentages of inattentiveness and bad turning from 


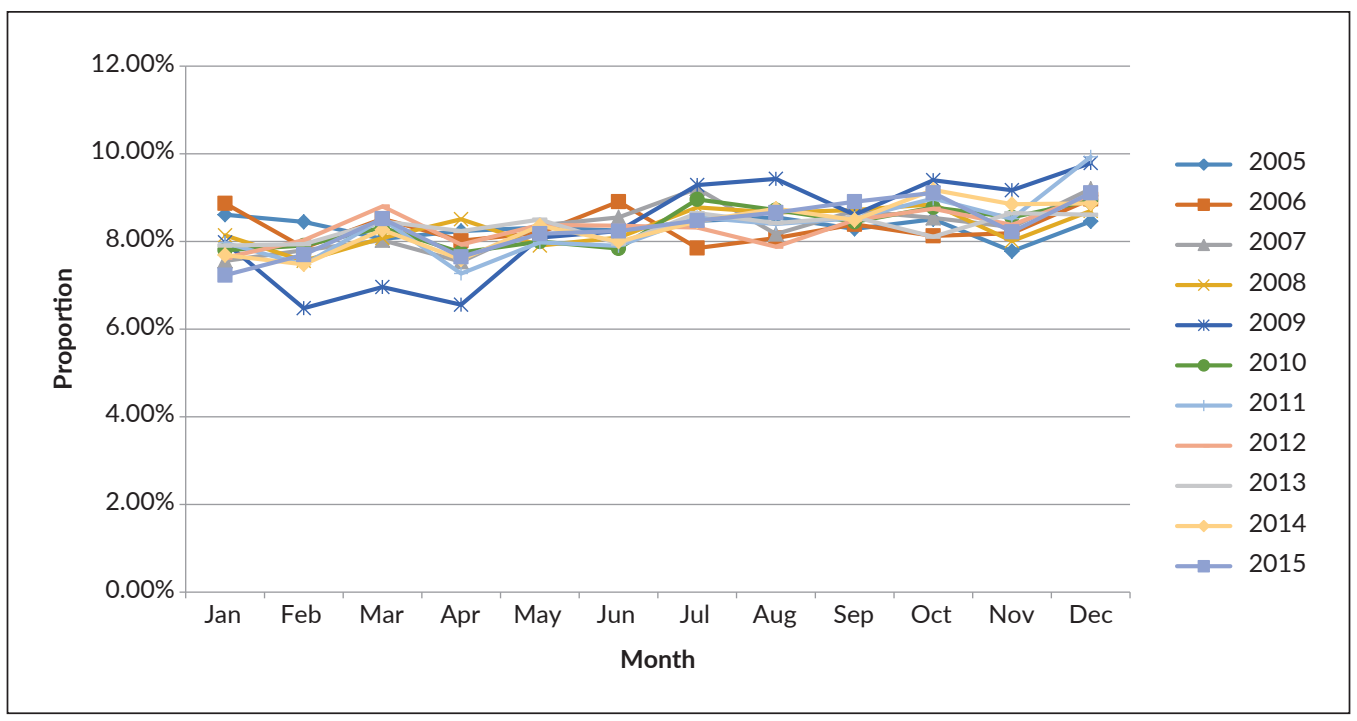

Figure 2. Road crash in Metro Manila (2005-2015) by month.

2005-2010 ranged between $28 \%$ and $41 \%$ and between $0.6 \%$ and $33 \%$, respectively. Fatigue and traffic violation made up $0.02 \%$ to $0.45 \%$ of the reported human factors of road crashrelated hospitalization cases in Metro Manila from 2005 to 2015. Alcohol-suspected causes accounted for $0.04 \%$ to $4.57 \%$ of the human errors reported (Figure 7).

Damage to property crashes is associated with bad overtaking, disobedience to traffic lights and traffic enforcers, and bad turning. For non-fatal and fatal crashes, the associated human errors are suspected alcohol use, inattentiveness, and speeding. The highest adjusted residual for both fatal and non-fatal(injurious) crashes is for inattentiveness (Table 2).

Human error was associated with years, suggesting that for some years, the number of crashes caused by human errors was significantly higher than expected. Alcohol-suspected crashes were significantly higher than expected for 2005 and 2011, with 2011 having the highest adjusted residual (Table 3). Inattentiveness-caused crashes were significantly higher than expected for years 2005 to 2010, with 2007

Table 2. Associations between classification of crash and human error

\begin{tabular}{llrrr}
$\begin{array}{c}\text { Classification } \\
\text { of Crash }\end{array}$ & $\begin{array}{c}\text { Associated } \\
\text { Human Errors }\end{array}$ & $\begin{array}{c}\text { Chi-Squared } \\
\text { Test }\end{array}$ & $\begin{array}{c}\text { Adjusted } \\
\text { Residual }\end{array}$ & p-value \\
$\begin{array}{l}\text { Damage to } \\
\text { Property }\end{array}$ & $\begin{array}{l}\text { Disobedience } \\
\text { to Traffic Lights/ } \\
\text { Enforcers }\end{array}$ & 211.22 & 14.53 & $<0.0001$ \\
& Bad Turning & 221.01 & 14.87 & $<0.0001$ \\
\hline Non-Fatal & Alcohol Suspected & 251.25 & 14.36 & $<0.0001$ \\
& Inattentiveness & 11535.22 & 105.64 & $<0.0001$ \\
& Speeding & 1566.46 & 38.14 & $<0.0001$ \\
\hline Fatal & Alcohol Suspected & 251.25 & 6.09 & $<0.0001$ \\
& Inattentiveness & 11535.22 & 14.84 & $<0.0001$ \\
& Speeding & 1566.46 & 8.93 & $<0.0001$ \\
\hline
\end{tabular}

having the highest adjusted residual. Bad turning was significantly higher from 2005 to 2007, while disobedience was significantly higher for 2005 to 2008. Speeding was significantly higher than expected from 2005 to 2010.

Table 3. Association between human error and years

\begin{tabular}{|c|c|c|c|c|}
\hline Human Error & $\begin{array}{l}\text { Associated } \\
\text { Years }\end{array}$ & $\begin{array}{c}\text { Chi-Squared } \\
\text { Test }\end{array}$ & $\begin{array}{l}\text { Adjusted } \\
\text { Residual }\end{array}$ & p-value \\
\hline \multirow{2}{*}{$\begin{array}{l}\text { Alcohol } \\
\text { Suspected }\end{array}$} & 2005 & \multirow[t]{2}{*}{4444.028} & 4.12 & \multirow[t]{2}{*}{$<0.0001$} \\
\hline & 2011 & & 63.14 & \\
\hline \multirow[t]{6}{*}{ Inattentiveness } & 2005 & \multirow[t]{6}{*}{73535.7} & 86.54 & \multirow[t]{6}{*}{$<0.0001$} \\
\hline & 2006 & & 104.12 & \\
\hline & 2007 & & 128.13 & \\
\hline & 2008 & & 102.63 & \\
\hline & 2009 & & 62.25 & \\
\hline & 2010 & & 68.74 & \\
\hline \multirow[t]{3}{*}{ Bad Overtaking } & 2006 & \multirow[t]{3}{*}{47523.54} & 127.00 & \multirow[t]{3}{*}{$<0.0001$} \\
\hline & 2007 & & 128.18 & \\
\hline & 2008 & & 80.98 & \\
\hline \multirow[t]{4}{*}{ Bad Turning } & 2005 & \multirow[t]{4}{*}{20173.1} & 55.05 & \multirow[t]{4}{*}{$<0.0001$} \\
\hline & 2006 & & 115.18 & \\
\hline & 2007 & & 25.76 & \\
\hline & 2008 & & 14.49 & \\
\hline \multirow{4}{*}{$\begin{array}{l}\text { Disobedience to } \\
\text { Traffic Lights/ } \\
\text { Enforcers }\end{array}$} & 2005 & \multirow[t]{4}{*}{13834.51} & 9.99 & \multirow[t]{4}{*}{$<0.0001$} \\
\hline & 2006 & & 76.52 & \\
\hline & 2007 & & 51.01 & \\
\hline & 2008 & & 50.07 & \\
\hline \multirow[t]{6}{*}{ Speeding } & 2005 & \multirow[t]{6}{*}{81984.08} & 156.53 & \\
\hline & 2006 & & 106.88 & \\
\hline & 2007 & & 75.98 & \\
\hline & 2008 & & 114.26 & \\
\hline & 2009 & & 73.08 & \\
\hline & 2010 & & 38.28 & \\
\hline
\end{tabular}


Human Error and other hazards associated to road crash

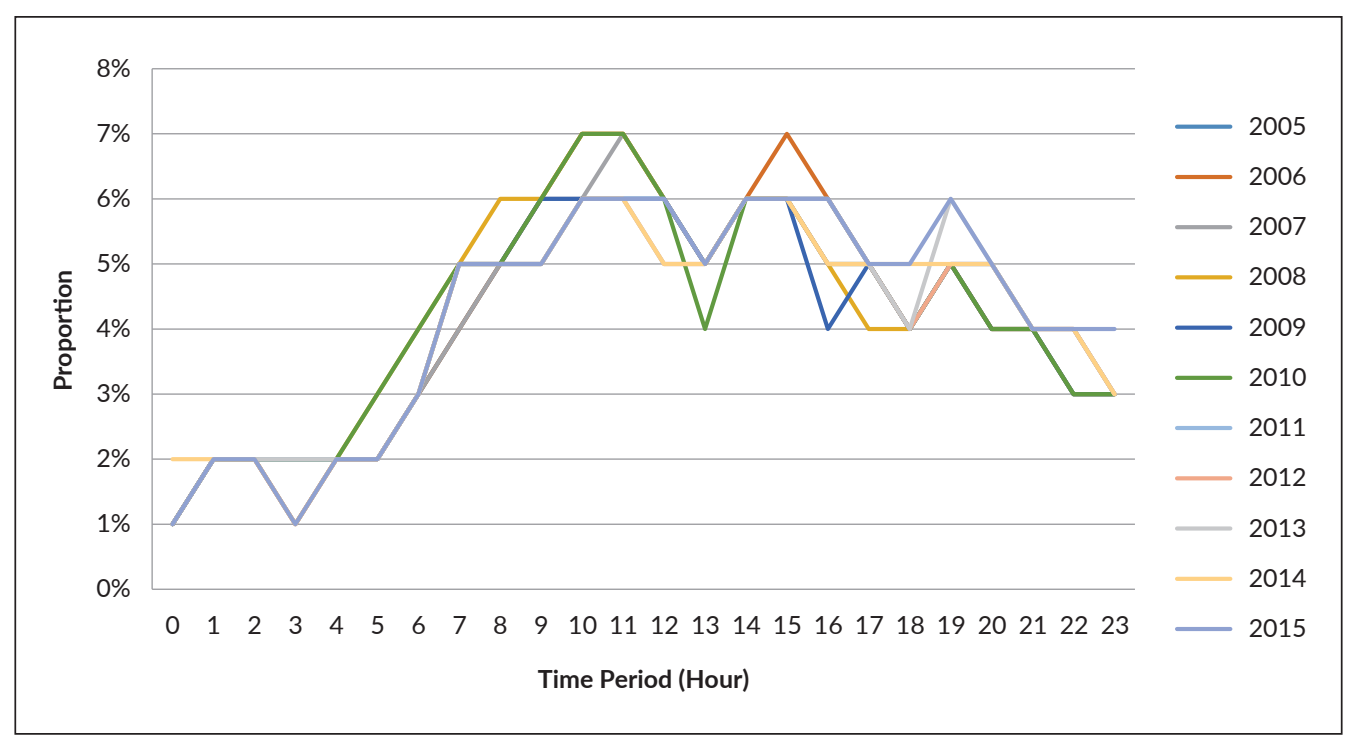

Note: 24-hour format.

Figure 3. Road crash by time of the day in Metro Manila (2005-2015).

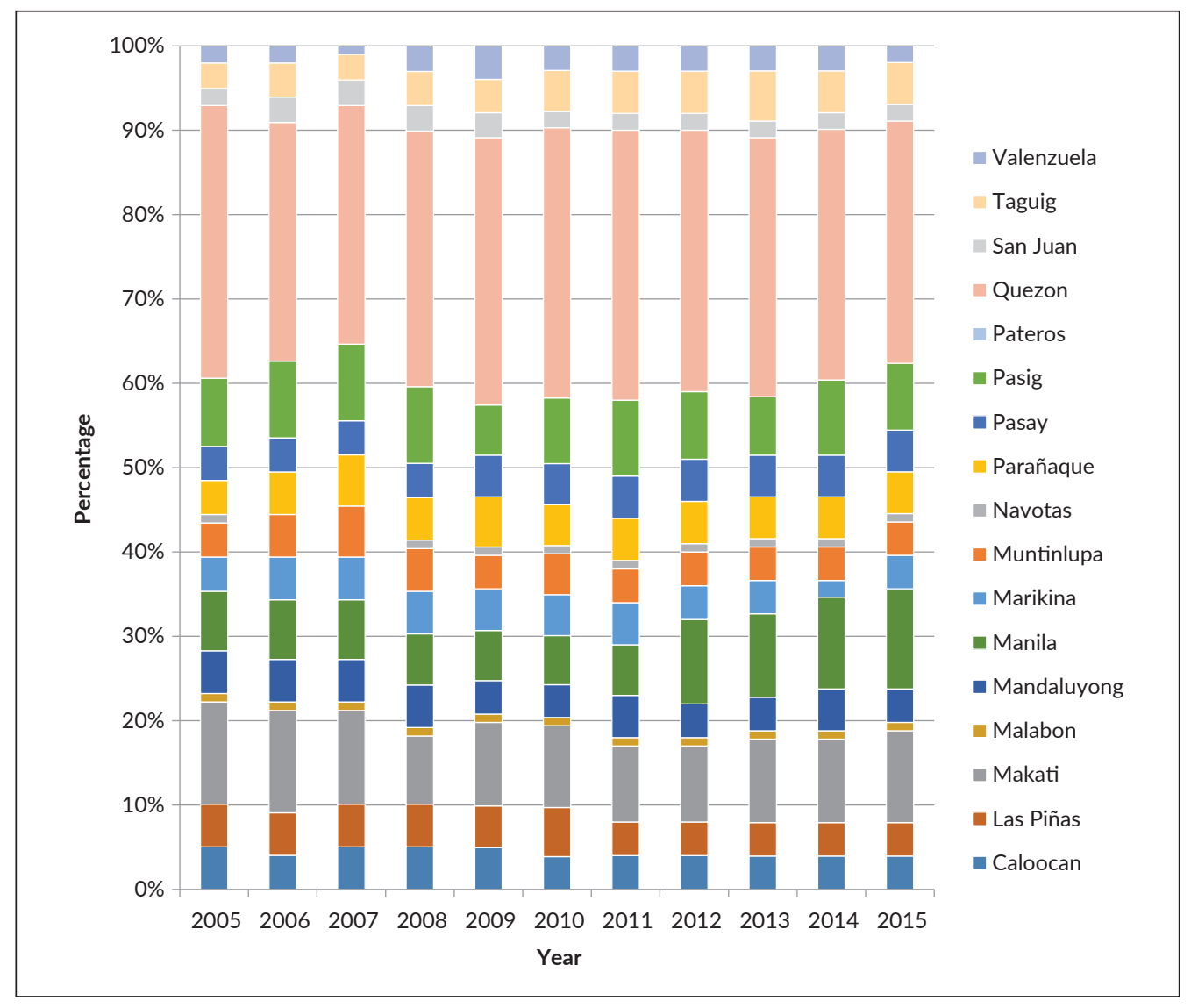

Figure 4. Road crash per city in Metro Manila (2005-2015). 


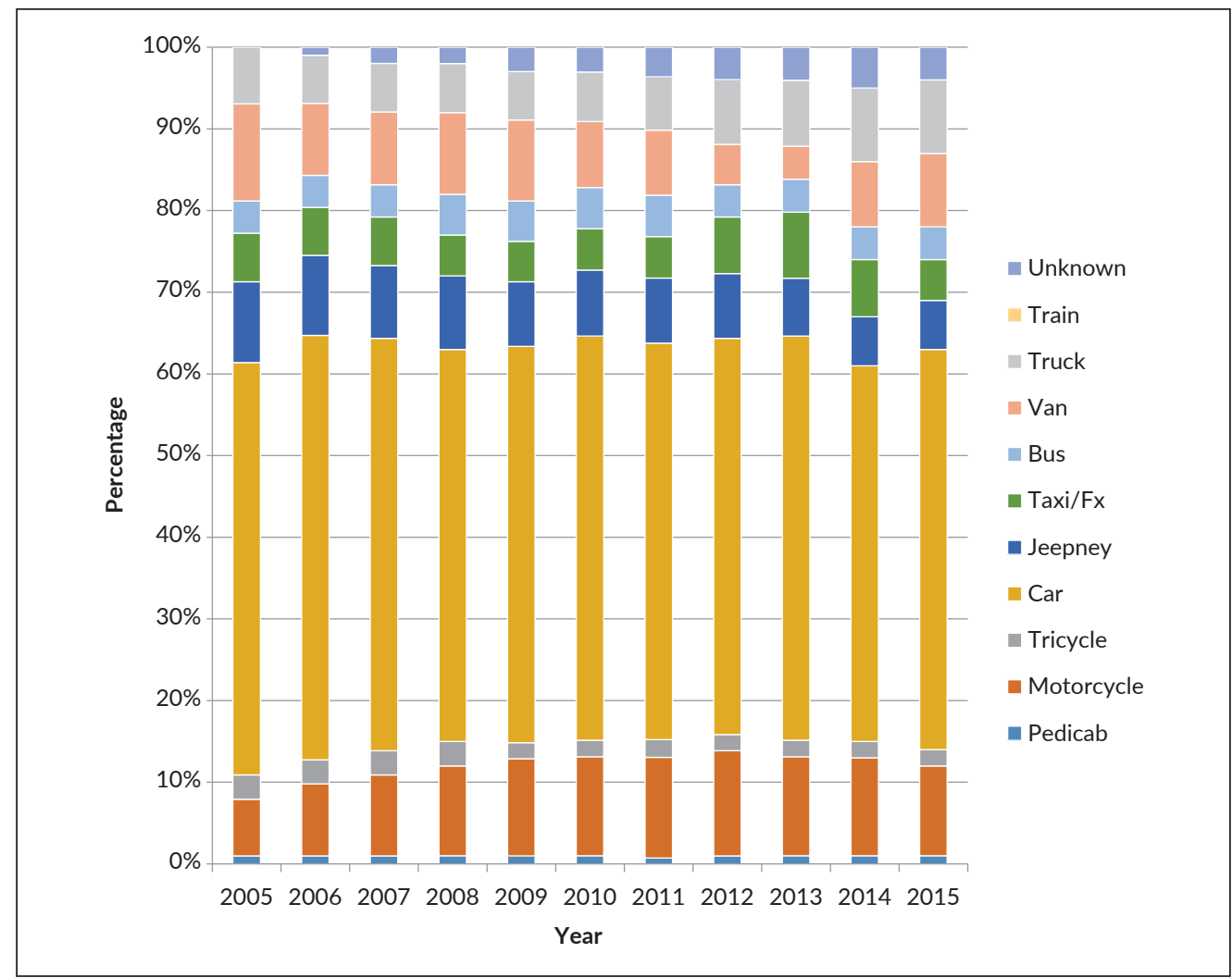

Figure 5. Road crashes in Metro Manila (2005-2015): by vehicle type.

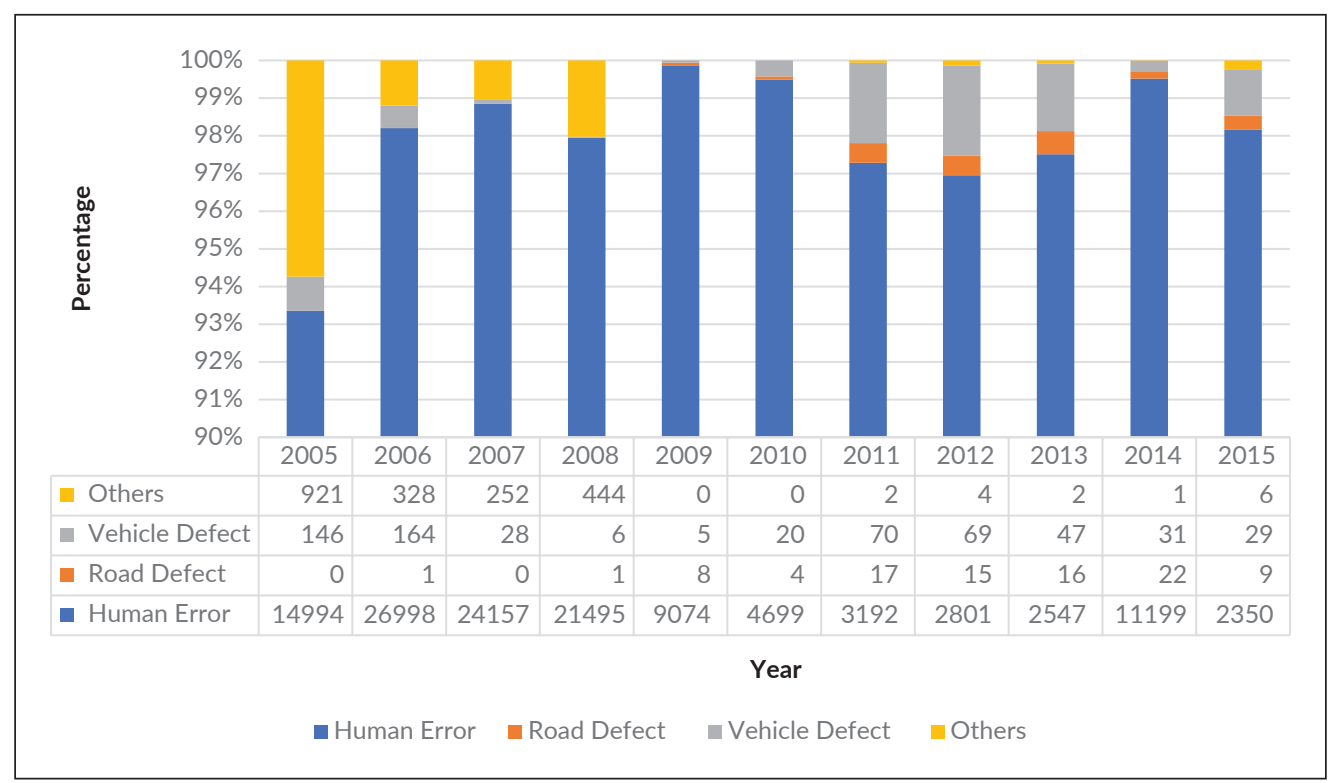

Figure 6. Road crash in Metro Manila (2005-2015): by ergonomic factors.

\section{DISCUSSION}

In this study, road crashes increased from 65,111 in 2005 to 95,615 in 2015 , and the number of fatalities increased from 348 in 2005 to 536 in 2015. This shows the increasing trend of road crashes in Metro Manila through the years, which is a trend that is also seen in other government surveillance. In the ONEISS, it was noted that vehicular crashes were the leading cause of unintentional injuries. ${ }^{2}$ Road crash-related injury cases showed a sharp increase from 14,499 in 2014 


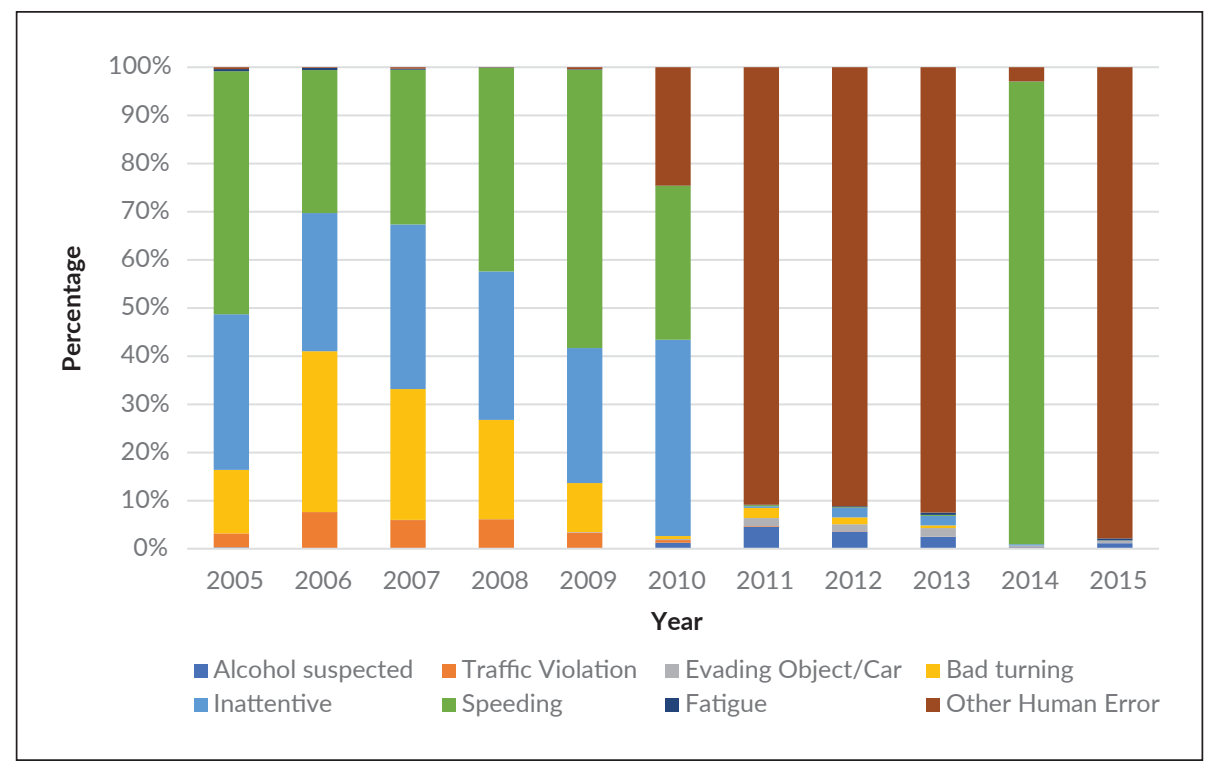

Note: The category 'other human errors' was stated as is in the database without further specification. Hence, it could not be further disaggregated.

Figure 7. Road crash in Metro Manila (2005-2015): by human error.

to 22,089 in 2015 . Similarly, the trend of road crash deaths in Myanmar from 2003-2014 also showed an increasing pattern. Road deaths in Myanmar increased to 1,853 in 2008, 2,496 in 2011, 3721 in 2013, and then to 4,313 in 2014. ${ }^{3}$ The same trend was found in Viet Nam between 1998-2007, Cambodia between 1995 and 2007 and Lao between 1990 and 2002, showing a very steep increase. ${ }^{4}$

From 2005 to 2010, the most reported human errors resulting from road crash-related-hospitalization cases in Metro Manila were: speeding, inattentiveness, and bad turning. The reported percentage rate of speeding from 2005-2010 ranged between 32\% and 58\%. Notably, in 2014, speeding (96\%) was the most commonly reported human error. The reported percentage rates of inattentiveness and bad turning between 2005 and 2015 ranged between 28\% and $41 \%$ and between $0.6 \%$ and $33 \%$, respectively. Verzosa and Miles $(2016)^{5}$ found in their study that most pedestrian fatalities occurred with speeding in high-volume traffic in a multilane roadway. In the study of Kaplan and Prato (2012), ${ }^{6}$ results showed that accident severity increases for very high (over $65 \mathrm{mph}$ ) and very low (under $20 \mathrm{mph}$ ) speed limits, at intersections as well as due to inattentiveness and risky driving behaviors. Other risky behaviors implicated in road crashes include dialing or texting on the cell phone, passengers, and in-vehicle sources resulting in increased or more severe injuries. ${ }^{7}$

The effects of alcohol on driving include impairment of brake reaction time, speed control, steering responsiveness, and lane control. ${ }^{8}$ In this study, alcohol-suspected cases accounted for $0.04 \%$ to $4.57 \%$ of the human errors reported for road crash-related hospitalization cases in Metro Manila from 2005 to 2015. WHO stated that drinking and driving in combination have been a well-known factor increasing the risk of a road crash and consequently, higher fatalities. ${ }^{4}$ In Hanoi, Vietnam, La et al. (2017) ${ }^{9}$ investigated the factors related to bus-related crashes and showed that drink-driving behavior was associated with bus-related crashes. Drunk driving has also been found as a significant factor affecting the severity of injuries in crashes in the study of Chu $(2014)^{10}$ among high-deck buses in long-distance driving on freeways in Taiwan, and with pedestrian injury severity in Illinois. ${ }^{11}$

An interesting observation is the combination of drunk driving and speeding, the two ergonomic factors that were shown in this study in the Philippines to be associated with road crashes. With driving under the influence, it was shown in the study of Scott-Parker et al. ${ }^{12}$ (2014) that substance-impaired driving was associated with speeding and risky driving intentions. These were all associated too with self-reported crashes and offenses, and police avoidance. Furthermore, there was also an aggregate association between illicit drug consumption with drunk driving behavior in Australia $^{13}$ and Brazil. ${ }^{14}$ In the latter study, $10.6 \%$ of the drivers $(n=232)$ recruited were positive for alcohol, 20.3\% had consumed either alcohol and/or drugs, and 15.5\% tested positive only for drugs specifically cannabis and cocaine, specifically cannabis and cocaine. ${ }^{14}$ Hence, in the computation of culpability ratio, it was higher for alcoholpositive drivers (three times higher) than that for alcohol-free drivers. The data also showed that for those who consumed drugs other than alcohol, the culpability ratio was 1.7 times that of drug-free drivers. ${ }^{14}$ 
In this study, fatigue and traffic violation made up $0.02 \%$ to $0.45 \%$ of the reported human factors of road crash-related hospitalization cases in Metro Manila from 2005 to 2015. Fatigue driving, termed as "silent killer" has been a major cause of traffic accidents. ${ }^{15}$ In factor of sleepiness was also found in another study among high-deck buses in longdistance driving on freeways wherein very significant risk factors to the severity of road crash injuries were driver fatigue, drivers or passengers not wearing a seat belt, reckless driving, and crashes occurring at interchange ramps. ${ }^{10}$

In another study, the odds of injury-involved crashes increased six-fold when the vehicle was driven by a driver who was not fully alert or sleepy $(\mathrm{OR}=5.7,95 \% \mathrm{CI}$ : 2.712.3). ${ }^{16}$ The amount of sleep is also a significant factor. Those who reported less than 6 hours of sleep during the past 24 hours also had a 6x fold increase in the odds of injuryinvolved crashes. Specifically, the population attributable risk for crashes associated with driving while not fully alert or sleepy after less than 6 hours of sleep was 34\%. ${ }^{16}$

There is also a common phenomenon now called sleep apnea. The study of Treager et al. (2009) ${ }^{17}$ showed there is an increased risk for crashes among commercial motor vehicle drivers with obstructive sleep apnea. Hence, sleep apnea should be treated especially among those whose driving is their main occupation, or among those who are always on the road.

In Malaysia, a study focusing on motorcyclists was conducted between June and August 2012 at access points on straight road sections of primary roads in the country. The researchers found that although there was a high rate of helmet compliance, there were unsafe acts of motorcyclists such as-not turning their heads to look for vehicles when entering a road with a high volume of traffic; did not comply with the stop line rule, especially those who made the opposite indirect right turn (OIRT); making a right turn into the primary road only within a short gap, resulting in a time lag of fewer than 4 seconds, thus leading to serious conflicts with other vehicles. ${ }^{18}$

Another interesting study also showed that in several collisions between cars and vulnerable road users such as pedestrians, the car driver failed to detect the pedestrian in time to avoid a collision. Based on the results of a social experiment with a group of motorists, the study suggested that there should be a modification of the speed limit in roads and zones which constitute a high risk of collision (key areas). ${ }^{19}$ As its applicability to the Philippine setting, speed management in consideration of intersections and zones of high risk should be implemented.

Road safety condition is also important in preventing road crashes. Optimal speed should be established depending on the road conditions. The optimal criterion is said to be the reliability of the driver's performance based on the various road conditions. ${ }^{20}$ In the Philippines wherein the road conditions and infrastructure are less optimal, conditions for speed limit should be established. The unsafe road was also shown in this study in Metro Manila to be associated with a road crash.

The road safety behavior of motorists is also an integral part of any program aimed at reducing road crashes and injuries. In the study of Chen et al. (2015) they came up with a road safety risk index using a clustering analysis to prioritize with risks that are the most prevalent in contributing to crashes and injuries. ${ }^{21}$ In an effort for improved road safety, a crowdsourcing tool was developed to allow African citizens to report and highlight road safety needs, to share opinions as well as to discuss solutions in their own countries. ${ }^{22}$ This may be a valuable tool for policymakers in the formulation of road safety programs.

Road safety communication campaigns are another strategy aimed at improving road safety behavior among motorists. In the design of road safety communication campaigns, Guttman underscored designing persuasive appeals for communication. Hence, consultation with behavioral scientists and mass media experts is encouraged. ${ }^{23} \mathrm{~A}$ dialogue platform was opened to experts and stakeholders to facilitate a constructive engagement and dialogue on road safety in Africa. ${ }^{22}$ This was further elaborated by Assailly in his paper wherein he identified important strategies in road safety education such as emotive experience regarding traffic experiences, e-learning, social norms marketing in changing behavior, and the multidimensionality of programs integrating the hard engineering aspects to the social sciences. ${ }^{24}$

There are other risk factors related to human error and ergonomics that can result in road crashes and traffic injury fatalities. Among these are showed that seatbelt use, vehicle type, collision type, contributing circumstance and driver/ vehicle action, number of vehicles involved in the accident, and accident location. ${ }^{25}$ In the study of Isa et al. (2011) ${ }^{26}$ the associated risk factors of being killed or severely injured among motorcyclists were the following-riding with a learner probationary license or without a license; riding with an improper helmet or without wearing any being involved in a crash that happens at built-up or rural areas and being involved in a head-on collision. Other risk factors among the pedestrian were not wearing contrasting clothing, divided highways, multilane highways, darkness, and heavy vehicles. ${ }^{11}$ These factors also need to be investigated in the Philippine setting.

This study, as a secondary analysis, is limited by the quality of the primary data obtained from the MMARAS. As described earlier, the MMARAS database obtains its data from blotter reports and reports from its traffic enforcers. The rigor of the road crash reporting by the concerned bodies will ultimately determine the quality of insights that can be produced. The study also is limited to the analysis of human error in road crashes. It is recommended that road crash reporting be strengthened in the Philippines to properly and more accurately appraise the road crash problem it is currently facing. 


\section{CONCLUSION}

Road crash fatality, which is indeed a concern in developed countries, is even more concerning in developing countries such as the Philippines. This study has shown that road traffic injuries and fatalities have nowadays become one of the most important public health issues in Metro Manila. The study has also shown human error was contributory to a road crash and related fatalities. The study also showed that the human error component, specifically alcohol suspected, Inattentiveness, and Speeding, are significantly associated factors in road crash fatalities, while bad overtaking, traffic violations and bad turning are associated with less severe road crashes. Among human error factors, it was found that speeding is the most reported, followed by inattentiveness, and bad turning. Other human errors noted were fatigue, evading objects/cars, traffic violation, and suspected alcohol use. It is recommended that road crash reporting in the Philippines be strengthened further to get better insights into on-road crashes.

\section{Acknowledgment}

This study was part of the overall program funded by the Emerging Interdisciplinary Research program of the University of the Philippines.

\section{Statement of Authorship}

Both authors participated in the data collection and analysis and approved the final version submitted.

\section{Author Disclosure}

Both authors declared no conflicts of interest.

\section{Funding Source}

This study was funded by the Emerging Interdisciplinary Research Program of the University of the Philippines.

\section{REFERENCES}

1. World Health Organization. Global status report on road safety 2013. Geneva: World Health Organization; 2013 [cited 2018 Jun]. Available from: https://www.who.int/violence_injury_prevention/road_safety_ status/2013/en/

2. Department of Health [Internet]. Philippines: Department of Health; c2021 [cited 2018 Jun]. Violence and Injury Prevention Program; [about 5 screens]. Available from: https://doh.gov.ph/violence-andinjury-prevention-program

3. Asian Development Bank. Myanmar Transport Sector Policy Note Road Safety [Internet]. Mandaluyong City: Asian Development Bank; 2016 [cited 2020 Dec]. Available from: https:/www.adb.org/sites/ default/files/publication/189080/mya-road-safety.pdf.

4. World Health Organization. Road safety in the Western Pacific Region: call for action [Internet]. Geneva: World Health Organization; 2009 [cited 2020 Dec]. Available from www.wpro.who.int/publications/ docs/RoadSafetyintheWPR.pdf.
5. Verzosa N, Miles R. Severity of road crashes involving pedestrians in Metro Manila, Philippines. Accid Anal Prev. 2016 Sep; 94:216-26.

6. Kaplan S, Prato CG. Risk factors associated with bus accident severity in the United States: a generalized ordered logit model. J Safety Res. 2012 Jul; 43(3):171-80.

7. Donmez B, Liu Z. Associations of distraction involvement and age with driver injury severities. J Safety Res. 2015 Feb; 52:23-8.

8. Mir MU, Khan I, Ahmed B, Razzak JA. Alcohol and marijuana use while driving--an unexpected crash risk in Pakistani commercial drivers: a cross-sectional survey. BMC Public Health. 2012; 12(1):145.

9. La QN, Duong DV, Lee AH, Meuleners LB. Factors underlying busrelated crashes in Hanoi, Vietnam. Trans Res Part F Traffic Psychol Behav. 2017 Apr; 46:426-37.

10. Chu HC. Assessing factors causing severe injuries in crashes of highdeck buses in long-distance driving on freeways. Accid Anal Prev. 2014 Jan; 62:130-6.

11. Pour-Rouholamin M, Zhou H. Investigating the risk factors associated with pedestrian injury severity in Illinois. J Safety Res. 2016 Jun; 57: 9-17.

12. Scott-Parker B, Watson B, King MJ, Hyde MK. "I drove after drinking alcohol" and other risky driving behaviours reported by young novice drivers. Accid Anal Prev. 2014 Sep; 70:65-73.

13. Curtis A, Coomber K, Hyder S, Droste N, Pennay A, Jenkinson R, et al. Prevalence and correlates of drink driving within patrons of Australian night-time entertainment precincts. Accid Anal Prev. 2016 Oct; 95(Pt A):187-91.

14. de Carvalho HB, Andreuccetti G, Rezende MR, Bernini C, Silva JS, Leyton V, et al. Alcohol and drug involvement in motorcycle driver injuries in the city of Sao Paulo, Brazil: Analysis of crash culpability and other associated factors. Drug Alcohol Depend. 2016 May 1; 162:199-205.

15. Zhang G. Yau KK, Zhang X, Li Y. Traffic accidents involving fatigue driving and their extent of casualties. Accid Anal Prev. 2016 Feb; 87:34-42

16. Herman J, Kafoa B, Wainiqolo I, Robinson E, McCaig E, Connor J, et al. Driver sleepiness and risk of motor vehicle crash injuries: a population-based case-control study in Fiji (TRIP 12). Injury. 2014 Mar; 45(3):586-91.

17. Tregear S, Reston J, Schoelles K, Phillips B. Obstructive sleep apnea and risk of motor vehicle crash: systematic review and meta-analysis. J Clin Sleep Med. 2009 Dec 15; 5(6):573-81.

18. Abdul Manan MM, Várhelyi A. Motorcycle fatalities in Malaysia. IATSS Res. 2012 Jul; 36(1): 30-9.

19. Rogé J, El Zufari V, Vienne F, Ndiaye D. Safety messages and visibility of vulnerable road users for drivers. Saf Sci. 2015 Nov; 79:29-38.

20. Batrakova A, Gredasova O. Influence of Road Conditions on Traffic Safety. Procedia Eng. 2016; 134:196-204.

21. Chen F, Wang J, Deng Y. Road safety risk evaluation by means of improved entropy TOPSIS-RSR. Saf Sci. 2015 Nov; 79:39-54.

22. Guttman N. Persuasive appeals in road safety communication campaigns: Theoretical frameworks and practical implications from the analysis of a decade of road safety campaign materials. Accid Anal Prev. 2015 Nov; 84:153-64.

23. Usami DS, Persia L, Meta E, Fava A, Azarko A, Saporito MR, et al. Improving road safety knowledge in Africa through crowdsourcing: the African Road Safety Observatory. Trans Res Proc. 2020; 45: 418-25.

24. Assailly JP. Road safety education: What works? Patient Educ Couns 2017; 100 Suppl 1:S24-S29.

25. Chang LY, Chien JT. Analysis of driver injury severity in truckinvolved accidents using a non-parametric classification tree model. Saf Sci. 2013 Jan; 51(1):17-22.

26. Isa MHM, Jawi ZM, Sarani R, Wong SV. Injury Severity Analysis of Accidents Involving Young Motorcycle Riders in Malaysia. J East Asia Soc Transp Stud. 2011; 9:1997-2010. 